\title{
DEFORMASI BENTUK DAN TEKSTUR RADIOLARIA DALAM KERAMIK INSTALASI
}

\author{
Dyah Retno Fitriani *)
}

\begin{abstract}
Passion, love, and interest can be an inspiration to an artist. That thing can be a stimulation in creating a work of art. Some scene of film Life of Pi shows an ocean view which glows at night became such an admiration to the writer. The astonishment then stimulated curiousities of the writer about that phenomenon. Finally, there came out the word Radiolaria. Radiolaria are tiny sized planktons which have holes and spikes in their bodies. The shape and texture of Radiolaria became an inspiration that later will be deformed and shaped into a ceramic instalation. Innovation and creation that arise in this work were also displayed using phospor as a medium to show the phenomenon of Bioluminesensi. The intention to introduce the shape and function of Radiolaria gives an enormous stimulation to the writer, so that this artwork was made to give an education through this work of art. The creation of this artwork began with making skecth planning, material choosing, up to the stage of creating which was done by some techniques, which are a cire perdue, pinch, slab, and decorating stage with the technique of piercing and twisting. After that, there was a drying stage, biscuit burning, glacing, glacing burning, phospor finishing, and displaying. Furthermore, the artwork was strenghten by some supporting theories, such as: ceramic theory, deformation, instalation, semiotic, and aesthetic theory.

This work is a ceramic applied art which was displayed in the varied colors and shapes instalation. Semiotic contains were slipped in this artwork and were hoped to create a good communication with the society and art lovers. This Radiolaria themed work of art was made to introduce Radiolaria to people in general with applying the touch of personal expression touch so that originality of this work would remains the same without fading the impression of the real Radiolaria.
\end{abstract}

Key Words: Deformation, Radiolaria, Ceramic Instalation.

\begin{abstract}
Abstrak
Kesukaan, kecintaan, ketertaikan akan suatu hal dapat menjadi sebuah inspirasi bagi seorang seniman, tentunya hal tersebut dapat menjadi sebuah rangsangan dalam menciptakan sebuah karya seni. Film Life of Pi yang dibeberapa scene nya memperlihatkan pemandangan laut yang dapat berpijar dimalam hari memberikan rasa takjub sehingga merangsang rasa ingin tahu tentang apa yang menyebabkan adanya fenomena tersebut, yang kemudian didapatlah kata Radiolaria. Radiolaria merupakan plankton yang berukuran sangat kecil dengan ciri khas memiliki lubang-lubang dan duri-duri pada tubuhnya. Bentuk dan tekstur Radiolaria ini dijadikan sumber ide yang kemudian akan dideformasi dan dijadikan keramik instalasi. Inovasi dan kreasi yang muncul dalam karya ini juga ditampilkan dengan menggunakan fosfor sebagai media untuk menunjukkan peristiwa Bioluminesensi. Rasa ingin memperkenalkan akan bentuk dan manfaat
\end{abstract}

\footnotetext{
* Dyah Retno Fitriani, Mahasiswa Program Pascasarjana Institut Seni Indonesia Yogyakarta
} 
Radiolaria memberikan dorongan yang begitu besar, sehingga diciptakanlah karya ini agar dapat memberikan edukasi baru melalui karya keramik instalasi.

Penciptaan karya ini diawali dengan membuat sketsa perancangan, pemilihan bahan, hingga tahap perwujudan yang dilakukan dengan beberapa teknik yaitu cetak tuang, pinch, dan slab dan tahap pendekorasian dengan teknik krawang, dan pilin. Kemudian tahapan pengeringan, pembakaran biskuit, pengglasiran, pembakaran glasir, finishing dengan fosfor, dan pendisplayan. Lalu diperkuat dengan beberapa teori pendukung seperti : teori keramik, deformasi, instalasi, semiotika, dan estetika.

Hasil karya ini merupakan seni kriya keramik yang didisplay secara instalasi yang memiliki variasi bentuk dan warna, dan kandungan semiotika yang disisipkan pada setiap karyanya sehingga diharapkan karya ini dapat berkomunikasi dengan masyarakat, dan penikmat seni dengan baik. Karya keramik dengan tema Radiolaria ini dimakudkan untuk memperkenalkan Radiolaria dikalangan awam dengan menerapkan sentuhan ekspresi pribadi sehingga orisinalitas karya tetap terjaga tanpa mengurangi kesan dari Radiolaria yang aslinya.

Kata Kunci : Deformasi, Radiolaria, Keramik Instalasi.

\section{PENDAHULUAN}

Ketertarikan, kesukaan, kecintaan seseorang akan sesuatu hal sifatnya tidak mutlak, relatif berbeda-beda, dan tidak bisa ditebak. Segala sesuatunya mempunyai latar belakang, baik itu pendidikan, lingkungan yang memengaruhi, maupun kepuasan batin yang dimiliki masing-masing individu. Begitu pula dengan berkarya seni, berbagai hal yang dapat diangkat oleh seorang seniman untuk dijadikan sumber inspirasi. Berkarya adalah sebuah tindakan untuk mewujudkan sebuah objek visual yang bersumber dari segala sesuatu yang mengganggu fikirannya, baik itu yang disukai, dibenci, yang menjijikkan, ataupun mengagumkan. Hal tersebutlah yang kemudian akan dieksplorasi, dirancang, dikreasikan, dan diwujudkan menjadi sebuah karya seni.

Hal yang mengganggu pemikiran hingga yang melandasinya untuk dijadikan sebuah sumber ide dalam berkarya, bermula dari melihat film Life of Pi. Film ini bercerita tentang seorang pria India yang bernama $\mathrm{Pi}$ Patel yang sedang terkatung-katung di lautan lepas bersama seekor harimau disebuah sekoci, karena kapal yang ditumpangi bersama keluarganya tenggelam. Film yang diadaptasi dari sebuah novel ini memperlihatkan pemandangan pada suatu malam ditengahtengah lautan yang luas, laut terlihat bersinar berkerlap-kerlip seperti bintang yang membuat $\mathrm{Pi}$ terkagum-kagum. Tidak hanya sampai di situ saja, pemandangan $\mathrm{Pi}$ saat terdampar di Pulau Karnivora juga memberikan decak kagum oleh siapa saja yang melihatnya. Diceritakan bahwa pulau tersebut seperti pulau normal pada siang hari, namun pada malam hari pulau tersebut berubah seperti pemangsa. Danau yang pada awalnya biasa saja berubah menjadi berkilau dan pepohonan seperti akan memakan siapa saja yang berada di pulau tersebut. Karena ketakutan $\mathrm{Pi}$ akhirnya memutuskan untuk meninggalkan pulau itu, setelah ia menemukan gigi manusia pada sebuah tanaman. Kekaguman akan fenomena laut dan yang terjadi di Pulau Karnivora pada film tersebut, membuat rasa penasaran yang besar untuk mencari tahu lebih jauh apakah di dalam 
kehidupan nyata hal tersebut bisa terjadi, atau hanya imajinasi dari film tersebut saja.

Beberapa riset dilakukan dengan cara membaca sinopsis film Life of Pi, mencari di internet, membaca buku, majalah, melihat video di youtube yang sekiranya berhubungan dan dapat memberikan informasi tenang peristiwa tersebut. Dari cara-cara tersebut didapatlah sebuah informasi bahwa fenomena laut tersebut memang dapat terjadi di lautan yang disebabkan oleh adanya plankton. Peristiwa adanya cahaya dilaut seperti bintang-bintang oleh para ahli disebut dengan Bioluminesensi (Nontji, 2008: 30).

Plankton merupakan sekelompok biota akuantik baik berupa tumbuhan maupun hewan yang hidup melayang atau terapung secara pasif di permukaan perairan, dan pergerakan serta penyebarannya dipengaruhi oleh gerakan arus walaupun sangat lemah (Sumich, 1992; Nybakken, 1993; Arinardi, 1997). Menurut Sumich (1992) plankton dapat dibedakan menjadi dua yaitu fitoplankton (plankton nabati) dan zooplankton (plankton hewan). Diantara kedua jenis plankton tersebut, yang paling banyak bisa melakukan Bioluminesensi adalah zooplankton. Setelah menggali lebih dalam tentang plankton, pembagian, klasifikasi dan bentuk yang dimiliki oleh plankton, terdapat zooplankton yang bernama Radiolaria.

Radiolaria memang merupakan sebuah kata asing bagi orang awam, karena pada umumnya kata tersebut kurang dikenal oleh masyarakat. Kekaguman pada Radiolaria bukan hanya karena dapat bersinar dimalam hari, namun juga dengan bentuk dan teksturnya yang sangat unik. Bentuknya bermacam-macam, namun dari semua Radiolaria, mempunyai bentuk visual yang hampir sama yaitu mempunyai lubang-lubang kecil dan duri-duri yang menyelimuti tubuhnya. Bentuk dari morfologi Radiolaria ini mirip dengan penyakit trypophobia, yaitu phobia akan melihat bentuk-bentuk yang mempunyai banyak lubang-lubang, sehingga orang yang terkena trypophobia akan merasakan geli, gatal, jijik, ketakutan bahkan histeris.

Selain tertarik pada bentuk visual dari Radiolaria, ketertarikan juga muncul dari manfaat yang dihasilkan oleh hewan ini. Selain manfaatnya yang digunakan sebagai bahan penggosok, Radiolaria yang sudah mati akan mengendap sebagai lumpur Radiolarian yang digunakan sebagai bahan peledak, yaitu achantometron dan collosphaera. Apabila mati, cangkang hewan ini tetap akan utuh dan menjadi fosil dalam waktu yang sangat lama sehingga berguna untuk menentukan umur lapisan bumi, dan sebagai indikator adanya minyak bumi.

Penciptaan karya yang mengangkat tema Radiolaria ini bertujuan untuk memperkenalkan kepada masyarakat bahwa hewan mikro ini selain mempunyai manfaat bagi kehidupan manusia, ternyata juga mempunyai bentuk yang sangat artistik, sehingga akan divisualisakan bentuk dan teksturnya yang akan diwujudkan menjadi karya keramik seni. Dalam perwujudannya akan digunakan tanah stoneware Sukabumi. Pembentukan bentuk global akan menggunakan cetak tuang, dan dekorasi dengan cara teknik krawang, dan pilin. Bahan tambahan lain yang akan digunakan adalah fosfor agar menambah estetika dan untuk menunjukkan kesan Bioluminesensi Radiolaria pada malam hari, yang dapat berpijar dalam kegelapan.

Berbagai hal yang melatarbelakangi penciptaan ini, oleh karena itu didapatlah rumusalan masalah bagaimana mengeksplorasi bentuk dan tekstur Radiolaria dalam keramik instalasi?, bagaimana proses perwujudan yang dilakukan dalam mendeformasi bentuk dan tekstur Radiolaria yang akan didisplay secara instalasi, serta 
menunjukan bagaimana dengan hasil karya dan suasana display yang akan ditampilkan dalam memvisualisasikan deformasi bentuk dan tekstur Radiolaria dalam keramik instalasi. Tujuan dari pembuatan karya ini selain untuk mengeksplorasi bentuk dan tekstur Radiolaria yang dapat memberikan semangat berkreativitas, juga dapat memberikan edukasi seperti manfaat, bentuk, sifat dan ciri-ciri Radiolaria. Selain itu untuk menunjukan proses penciptaan dalam proses pendeformasian bentuk dan tekstur Radiolaria dalam keramik instalasi serta menunjukan hasil karya dan suasana display yang ditunjukan dalam karya keramik ini.

\section{METODE PENCIPTAAN}

Keramik menurut kamus bahasa Indonesia adalah : "Tanah liat yang dibakar, dicampur dengan mineral lain : barang-barang tembikar (porselen) " (Moeliono, 1998: 423). Sedangkan menurut Astuti (1997:1), "Kata keramik berasal dari bahasa Yunani 'keramos' yang berarti periuk atau belanga yang terbuat dari tanah yang melalui pembakaran suhu tinggi “. Ditelusuri lebih jauh, keramos merupakan nama dari salah satu dewa Yunani. "Dalam mitologi Yunani, keramos merupakan dewa pelindung dari para pembuat kerajinan tanah liat atau keramik. Keramos adalah putra dari Dewa Baccus dan Dewi Ariadne " (Astuti, 1997:1).

Pada mulanya keramik hanya sebagai bahan kerajinan namun seiring dengan perkembangan, keramik mulai dijadikan media untuk berekspresi oleh seniman, yang berbeda satu sama lainnya karena pengalaman dan kerjasama dengan bahan bagi setiap seniman tentu tidak sama. Ekspresi menurut kamus Umum Bahasa Indonesia adalah : "Pengungkapan atau proses menyatakan (yaitu memperlihatkan atau menyatakan maksud, gagasan, perasaan, dsb" (Moeliono, 1998: 223). Seniman disebut pula perupa atau creator, selalu bergelut dengan kreativitas melalui eksperimen, inspirasi dan inovasi. Dalam pergaulan yang lama antara seniman dan bahan, umumnya akan terjadi suatu pengenalan yang terus menerus yang akhirnya menyatukan seniman dan bahannya. Seniman begitu mengenal bahannya, sehingga ia telah mengetahui apa yang dapat seniman capai dengan bahan tersebut dan bagaimana cara yang paling tepat untuk memanipulasi bahan dan mewujudkan suatu ide dan teknik tidak lagi terjadi tarik-menarik, melainkan suatu kerja sama akrab yang akan menghasilkan karya akhir yang diinginkan. Inilah yang akan melahirkan apa yang disebut sebagai "sentuhan-sentuhan pribadi seorang seniman", yang berbeda satu sama lainnya karena pengalaman dan kerja dengan bahan bagi setiap seniman tentu tidak sama. Timbul Raharjo mengatakan bahwa sebuah karya seni merupakan cerminan jiwa penciptanya. Bentuk-bentuk karya seni keramik itu merupakan ungkapan yang timbul dan tumbuh dalam batin sang seniman (Raharjo, 2001:4). Sedangkan Hildawati Soemantri mengatakan bahwa pendekatan keramik harus mulai dari pengetahuan dasar mengenai bahan tanah liat, serta menguasai skill teknis. Hanya setelah itulah dia dapat menuju ketingkat berikutnya (Soemantri via Carla Biapoen, 2005: 83).

Radiolaria berakar dari kata latin radiolus, radius dan ray yang berarti ciri umum mereka, yaitu kaki-kaki semu, tanduk, dan duri atau serupa pedang yang memancar secara radial (radiating pseupodia atau radiating spicule). Duri-duri kecil mereka sering disebut langsung sebagai ray atau beam. Kata ridius juga mencirikan cangkang mereka yang memiliki simetri radial. Radiolaria adalah binatang plankton yang hidup di lautan. Plankton adalah makhluk renik, bisa binatang, bisa juga tumbuhan, yang hidup di air. Radiolaria adalah plankton yang disebut immotile atau tidak bisa bergerak sendiri, 
mereka berpindah kesana-kemari tergantung arus air yang membawanya. Walaupun ukurannya kecil antara $30 \mu \mathrm{m}(0,00003 \mathrm{~m})$ hingga $0,2 \mathrm{~mm} \quad(0,0002 \mathrm{~m})$, Radiolaria termasuk binatang renik yang bisa terawetkan menjadi fosil selama jutaan tahun. Radiolaria yang berukuran umumnya antara 50-100 $\mu \mathrm{m}$ atau pada kisaran setebal sehelai rambut manusia, diketahui telah menghuni lautan sejak zaman kambrium atau 530 juta tahun yang lalu. Selama perjalanan waktu yang sangat lama itu, Radiolaria berevolusi dengan berbagai penampilan yang menggagumkan.

Fauna yang dikenal dengan nama Radiolaria ini mulai diperkenalkan secara ilmiah pada tahun 1834 atas jasa peneliti dari Jerman, F.J.F Meyen. Namun baru dalam tahun 1858 nama Radiolaria digunakan dalam sistem taksonomi oleh ahli Biologi Jerman, Johannes Muller. Dan seorang ahli biologi Jerman lainnya Ernest Haeckel (1834-1919) juga dijuluki sebagai pelopor penelitian Radiolaria, karena pada tahun 1887 murid dari Johannes Muller ini menerbitkan monografi berisi 3.508 spesies baru Radiolaria berasal dari contoh sedimen dasar laut dan contoh planton hasil ekspedisi bersama kapal riset HMS Challenger (www.geomagz.geologi.esdm.go.id).

Pada umumnya kerangka dari Radiolaria ini terbuat dari bahan silika, namun ada juga marga dari Radiolaria ini yang kerangkanya terbuat dari strontium sulfat, misalnya Achantaria. Strontium adalah unsur kelumit (trace element) di laut, hampir tidak dapat terukur karena laut yang sangat dalan, tetapi hewan ini mampu mengakumulasi unsur kimia ini dalam kerangkanya (Nontji, 2008: 113).

Karena umumnya Radiolaria mempunyai kerangka dari bahan silika yang tidak gampang terurai, maka peninggalannya berupa fosil dapat terekam dengan sangat baik dari jutaan tahun lalu seperti yang dikatakan Anugerah Nontji (2008: 115), jejak fosil Radiolaria sudah terekam dari era Paleozoic atau kira-kira 600 juta tahun lalu. Karena itu pula fosil Radiolaria banyak dimanfaatkan dalam kajian-kajian lingkungan purba (paleo-environtment). Karena kerangka dari silika itu pula, Radiolaria yang mati dan tenggelam akan dapat membentuk sedimen berupa selut atau nenes (ooze) di dasar laut yang dikenal dengan selut Radiolaria (Radiolarian ooze). Sedimen dasar laut-dalam di dunia ini, terutama yang ke dalamannya lebih dari $3800 \mathrm{~m}$ didominasi oleh selut Radiolaria. Diperkirakan sekitar 3,7 juta km2 luas dasar laut-dalam ini tertutup oleh selut Radiolaria.

Informasi mengenal biologi Radiolaria plankton di Indonesia masih sangat terbatas, lebih banyak dikaji dari aspek sedimentologi dan geologinya. Paverd dan Bj'rklund (1989) dalam penelitiannya di Laut Banda misalnya, menemukan kerangka Radiolaria terbanyak pada sedimen dengan ke dalaman 950-4899 m, sedangkan penelitian oleh Adisputra (1989) dibagian perairan Samudra Hindia sebelah selatan Nusa Tenggara, yang dikenal dengan Palung Jawa (Java Trench), menunjukkan bahwa pada dasar laut dengan ke dalaman lebih dari $6600 \mathrm{~m}$ sedimennya semata-mata terdiri dari Radiolaria (Nontji, 2008: 115).

Pada malam hari orang sering dapat melihat cahaya kelap-kelip bagai kunangkunang di dalam laut tanpa mengerti bahwa itu disebabkan oleh plankton. Fenomena alam tersebut disebut dengan Bioluminesensi. Adalah emisi cahaya yang dihasilkan oleh makhluk hidup yang disebabkan oleh adanya reaksi kimia tertentu. Bioluminensi atau cahaya hayati ini sebenarnya merupakan reaksi dari enzimatis lusiferin-lusiferase yang menghasilkan cahaya dingin kebiru-biruan. Fungsi plankton melakukan reaksi ini adalah untuk pertahanan dari pemangsa, predasi, dan sinyal kawin (Nontji, 2008: 30). 
Radiolaria yang menjadi inspirasi tersebut kemudian dalam karya ini akan dideformasi menjadi spesies baru seperti yang diungkapkan oleh Dharsono (2004: 43), penggambaran bentuk yang menekankan pada interpretai karakter, dengan cara mengubah bentuk objek dengan cara menggambarkan objek tersebut dengan hanya sebagaian yang dianggap mewakili, atau pengambilan unsur tertentu yang mewakili karakter hasil interpretasi yang sifatnya sangat hakiki. Pendeformasian bentuk dan tekstur Radiolaria kemudian dipresentasikan dengan pendisplayan yang dilakukan secara intsalasi yang menurut Niamh Ann Kelly (2010: 3) adalah sebagai $A$ broad term applied to a range of arts practice which involves the installation or configuration of objects in a space, where the totality of the object and the space comprise the artwork.

Metode Pendekatan dalam penciptaan karya ini melalui estetis yaitu metode yang digunakan mengacu pada nilainilai estetis yang terkandung dalam seni rupa, sehingga mempengaruhi seni tesebut seperti garis (line), bentuk (shape), warna (color), tekstur (texture) dan lain-lain (Feldman, 1967). Pendekatan estetis adalah cara pandang yang bertolak dari segi pola-pola artistik untuk membangun pemahaman atas unsur-unsur seni rupa. Estetik adalah tujuan utama dalam penciptaan karya yang bersumber inspirasi dari Radiolaria ini. Ketentuan basic desain yang telah dipelajari dalam studi seni kriya sebagai bagian bawah sadar yang secara sepontan keluar menjadi kaidah baku dalam melakukan penciptaan seni kriya, yang dimulai dari sketsa sampai pada tahap penyelesaian. Perjalanan panjang itulah yang dimaksud dengan proses artistik dalam merekonstruksi sebuah sumber insprasi sampai perwujudan karya yang dinikmati di ruang pamer (Dharsono, 2004).

Semiotika yaitu cara yang digunakan untuk mengetahui apakah dalam sebuah karya seni memiliki makna symbol, index, dan icon. Pendekatan ini sebenarnya dipakai sebagai pemaknaan karya atas maksud dan tujuan secara filosofis. Cerita dibalik simbol yang ada, sehingga dalam membuat karya pertimbangan dengan semiotik menjadi penting ketika karya itu berkomonikasi dengan penikmat. Maka pendekatan semiotik diyakini dapat memberikan roh atas karya yang dibuat. Pemaknaan dapat berisi sebuah harapan bagus, hidup lebih baik, cinta, kasih sayang dan berbagai maksud baik dalam kehidupan. Harapan itu sebagai doa agar kepuasan pribadi ini dapat memberikan dampak yang baik bagi penimatnya.

Metode penciptaan adalah cara yang dipakai dalam pengumpulan data di lapangan maupun studi lainnya guna mendukung kelancaran proses penciptaan karya seni (Gustami, 2007: 329). Eksplorasi yaitu proses pencarian bentuk-bentuk melalui sketsa yang akan dipilih untuk pembuatan karya yang akan diciptakan. Perwujudan yaitu proses pembuatan karya seni yang dimulai dari persiapan mengolah bahan, menyiapkan alatalat, proses pembentukan, dan pembakaran.

Proses penciptaan karya ilmiah ini diperlukan data acuan mengenai Radiolaria untuk memperoleh keakuratan dan pembuktian adanya keterkaitan dengan konsep karya sebagai bahan referensi. Data diperoleh melalui media majalah, internet, dan buku-buku terkait. Sebagai berikut: 


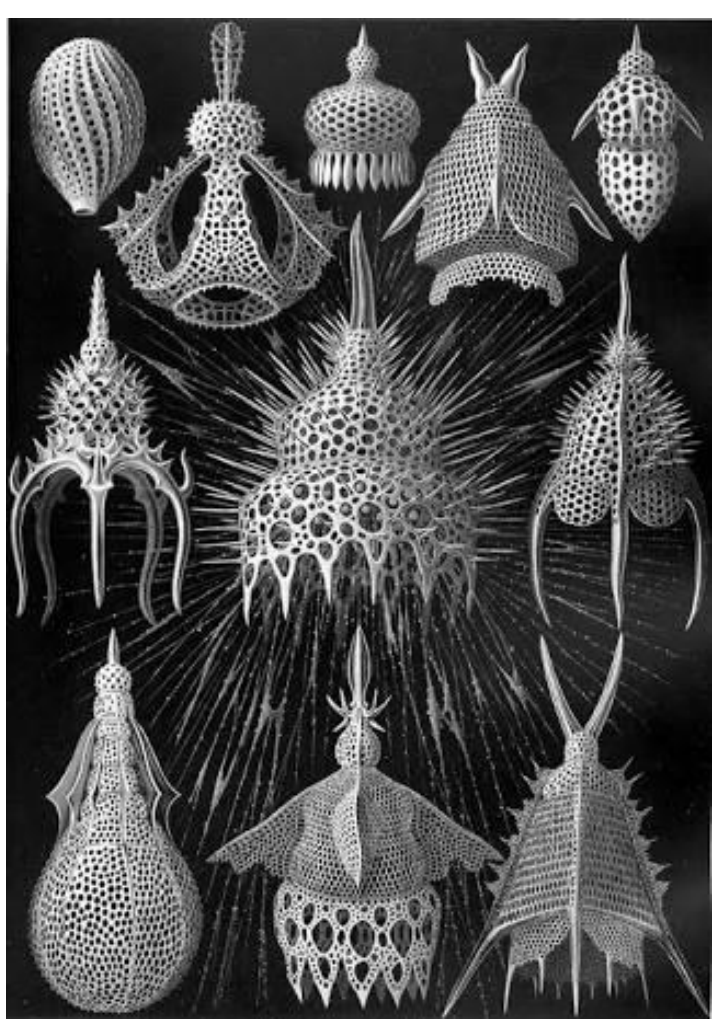

Gambar. 1 Berbagai bentuk Radiolaria yang pernah digambar oleh Ernest Haekel.

(Sumber : www.Radiolaria.org, 5 Mei 2016)

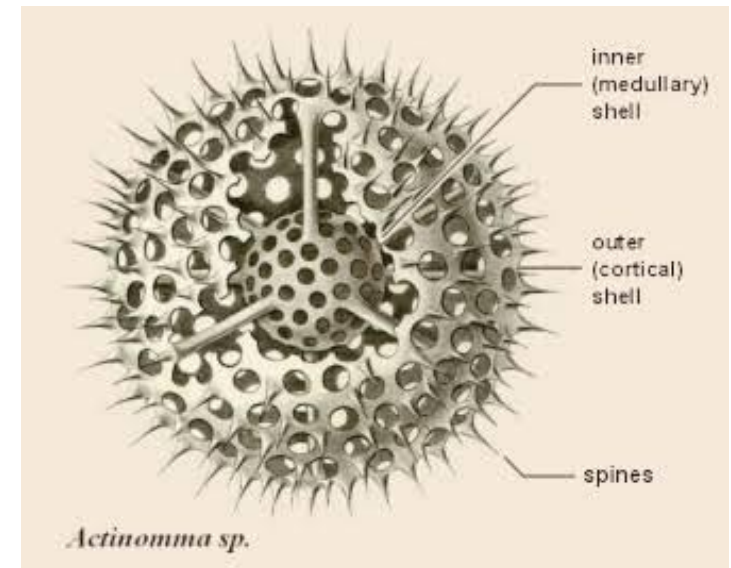

Gambar. 2 Pembagian nama-nama secara morfologi dari Actinoma sp. (Sumber : www.Radiolaria.org, 28 Februari 2016 20:03 )

\section{HASIL DAN PEMBAHASAN}

Berikut ini adalah perencanaan karya yang akan diawali dengan pembuatan sketsa terpilih:

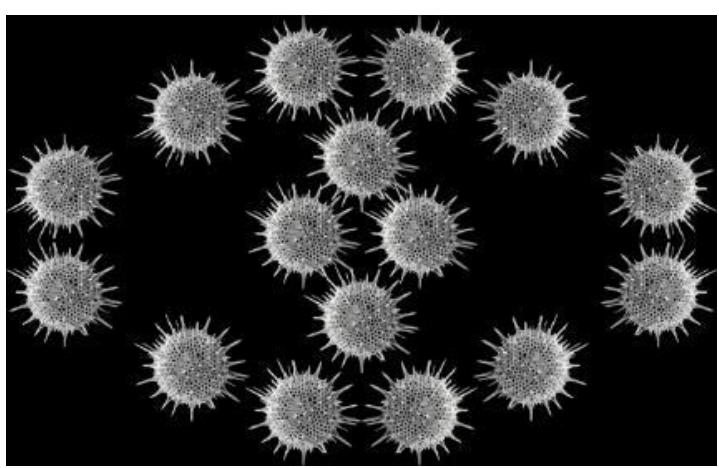

Gambar. 3 Sketsa rancangan karya berjudul Bumiku Buruk Rupa.

(Sketsa : Dyah Retno Fitriani)

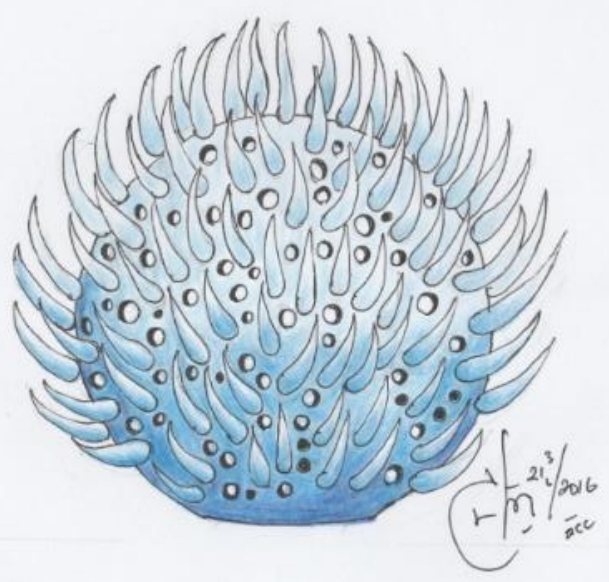

Gambar. 4 Detail sketsa rancangan karya berjudul Bumiku Buruk Rupa

(Sketsa : Dyah Retno Fitriani)

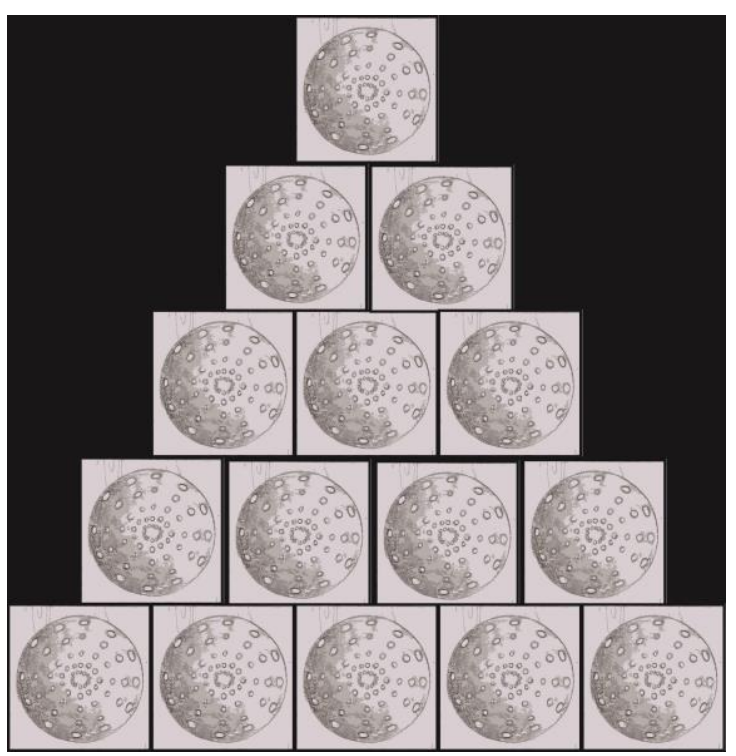

Gambar. 5 Sketsa rancangan karya berjudul Imperfection 


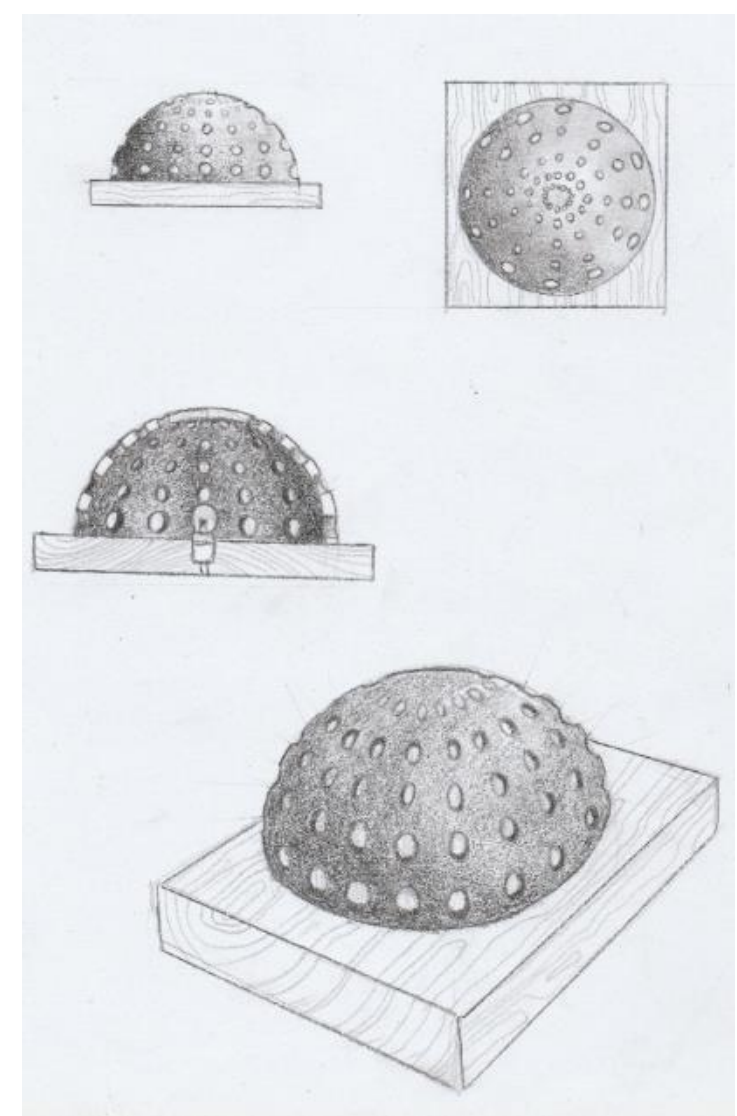

Gambar. 6 Gambar perspektif sketsa rancangan karya berjudul Imperfection

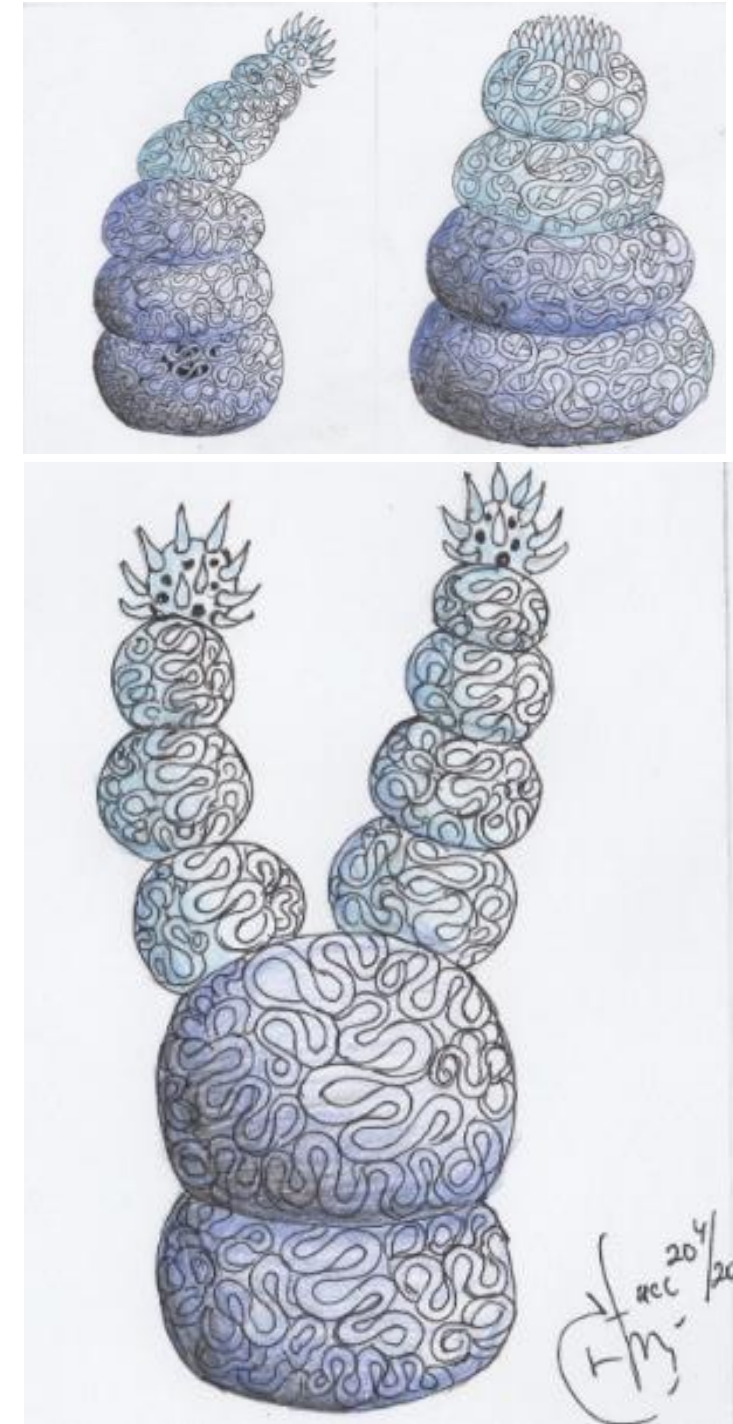

Gambar. 7 Sketsa rancangan karya dengan judul Infinity Craft in Social Paradigm

Bahan baku utama untuk mengerjakan karya ilmiah menggunakan bahan utama tanah liat jenis stoneware yaitu tanah liat Sukabumi berwarna abu-abu pada saat keadaan basah, bahan lainnya berupa glasir, gypsum dan fosfor. Alat yang mendukung dan sesuai dengan pengerjaan karya ilmiah ini yaitu pisau, satu set butsir, plastic, triplek, spray gun, spon, senar pemotong, dan lain-lain.

Teknik hand building dan slip casting digunakan dalam pembuatan karya karya seni keramik ini dan beberapa teknik dekorasi diantaranya teknik krawang dan teknik pilin. Ada beberapa tahap yang harus di kerjakan dalam prmbuatan karya karya seni keramik ini 
diantaranya yaitu: Tahap awal pengolahan bahan, tahap kedua model dan cetakan, tahap ketiga pembentukan, tahap keempat pengeringan, tahap kelima pembakaran biskuit sampai suhu $800^{\circ} \mathrm{C}$, tahap keenam pengglasiran, dan tahap ketujuh pembakaran glasir mencapai suhu $1200^{\circ} \mathrm{C}$. (Billington, 1974)

\section{Karya}

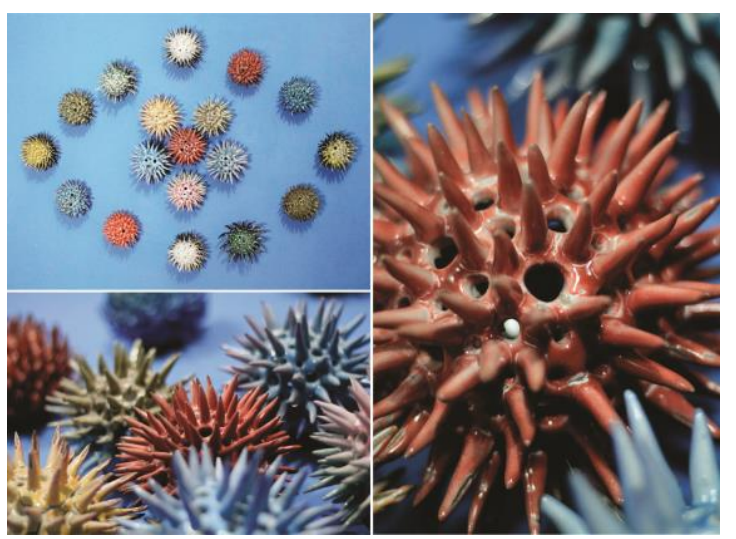

Gambar. 8 Karya 1, Judul : Bumiku Buruk Rupa, Ukuran : Variable Dimention, Teknik : Cetak tuang, krawang, pilin, Bahan : Sukabumi Stoneware, Finishing : Glasir, Suhu Bakar : $1200^{\circ} \mathrm{C}$, (Foto : Eko Atmojo, 2016)

Bentuk visual dari karya ini berupa bola yang memiliki lubang-lubang bervariasi dengan tekstur duri-duri ditubuhnya dengan finishing warna glasir yang dibuat dua warna dalam satu bola dengan memadu-madankan estetika warna-warna bergradasi maupun warna kontras. Terdapat 23 bola yang akan disusun membentuk sebuah simbol mata. Bumi Buruk Rupa merupakan sebuah penegasan dalam judul yang bermaksud dalam mengkritik lingkungan yang terjadi sekarang. Bumi merupakan salah satu planet dalam sistem tata surya ini yang memiliki banyak air, dapat dihuni manusia, dan tumbuh beraneka ragam flora dan fauna. Dalam cerita karya Bumiku Buruk Rupa adalah sebuah kritik tentang lingkungan yang kian lama kian tidak terjaga, atmosfer berlubang, pohon-pohon terbabat habis, limbah meracuni dan mengotori sungai-sungai hingga laut, gedung gedung pencakar langit tumbuh dan memenuhi hampir seluruh daratan di bumi ini. Konon ceritanya jika bumi akan hancur, manusia akan diungsikan dan dipindahkan ke planet lain, lalu menikmati dari planet itu bahwa bumi yang telah memberikan kehidupan pada kita sekarang ini perlahan mulai menua, buruk rupa kemudian hancur.

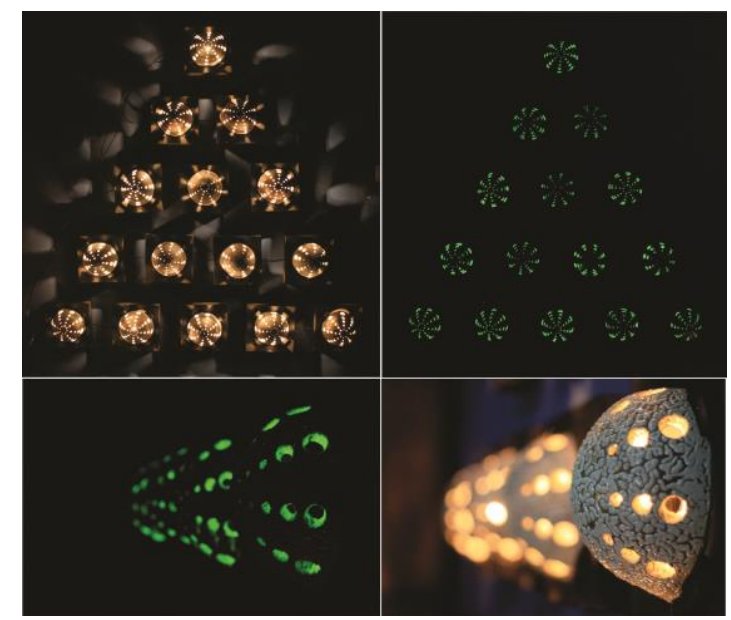

Gambar. 9 Karya II, Judul : Imperfection, Ukuran : Variable Dimention, Bahan : Sukabumi Stoneware, Finishing : Glasir, Suhu Bakar : $1200^{\circ} \mathrm{C}$, (Foto : Eko Atmojo, 2016)

Karya yang berarti Ketidaksempurnaan ini diangkat karena prosesnya yang mengalami sedikit kendala dalam hal pengglasiran dan pembentukan yang terlalu tipis hingga setelah dibakar glasir keramik menjadi terbelah karena tidak bisa menahan beban. Sehingga Imperfection dirasa meakili karya ini. Adapun pesan yang ingin disampaikan bahwa kita sebagai manusia memang tidak ada yang sempurna, namun ketidaksempurnaan tersebut juga dapat diubah menjadi sesuatu hal yang sempurna apabila kita berusaha keras untuk memperbaiki setiap kesalahan, rendah hati, dan bersyukur akan keadaan dan ciptaan yang diberikan oleh Tuhan. 


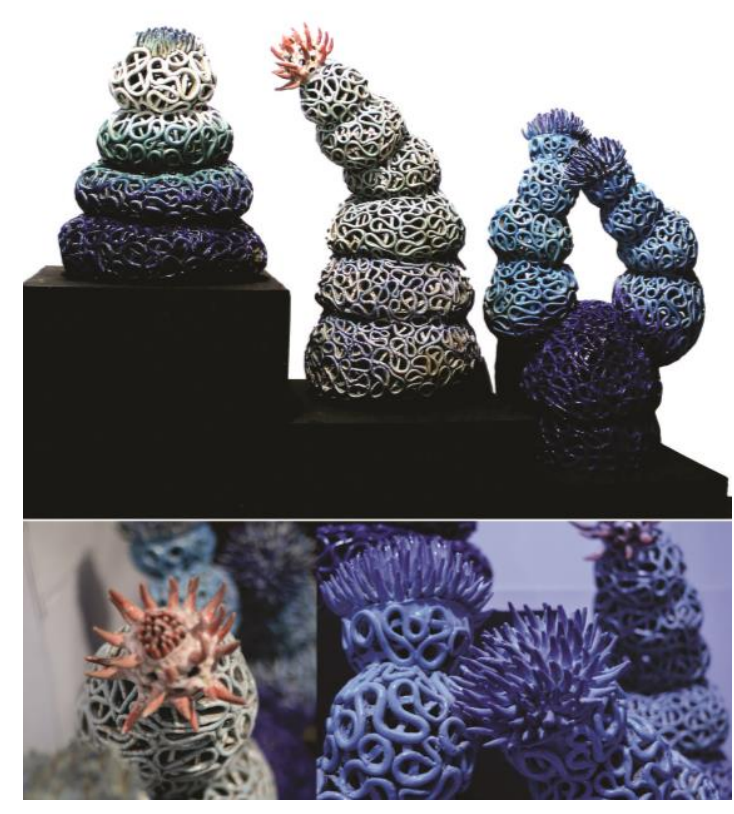

Gambar. 10 Karya III, Judul : Infinity Craft in Social Paradigm, Ukuran : Variable Dimention, Bahan : Sukabumi Stoneware, Suhu Bakar : $1200^{\circ} \mathrm{C}$, Finishing : Glasir, (Foto : Dyah Retno Fitriani dan Eko Atmojo, 2016)

Karya ini memiliki bentuk visual yang berasal merupakn hasil pendeformasian dari penggabungan spesies Radiolaria yang bernama eucyridium. $S p$ dan actinomma. $S p$ sehingga terciptalah intepretasi baru yang diwujudkan dalam karya keramik. Teknik yang digunakan dalam proses pembetukan adalah pinch dengan tambahan dekorasi dengan menggunakan teknik pilin untuk membuat alur-alur dan tekstur duri-duri yang kemudian di krawang pada bagian bodinya sehingga tercipta motif yang terlihat rumit. Bentuk pertama dibuat memanjang keatas dengan lipatan-lipatan yang diujung bagian atasnya terdapat duri-uri, bentuk kedua berbentuk memanjang keatas dengan lipatan-lipatan yang semakin keatas semakin miring, dan bentuk ketiga dibuat bercang menjadi dua. Finishing glasir dalam karya ini menggunakan warna biru tua dan biru muda yang digradasi.

Infinity Craft in Social Paradigm yang berarti ketidakterbatasan kriya dalam paradigma sosial merupakan sebuah judul yang diambil dalam mewakili apa yang dirasakan, analisis dalam lingkungan berkesenian khususnya di kriya yang akhirnya dapat tercurah sedikit di dalam karya ini. Pengertian kriya semakin tidak menentu, dan tidak terbatas dalam paradigma atau pandangan sosial yang menjadikan orang yang baru mengenal kriya bertanya-tanya dan kebingungan dengan apa yang dimaksud dengan kriya. Beberapa orang berpendapat bahwa kriya merupakan seni terapan yang dapat di much production, hanya berupa kerajinan yang dapat ditemukan di desa-desa wisata. Adapula yang berpendapat bahwa kriya adalah sesuatu yang adiluhung, yang dibuat dengan mementingkan teknik craftmanship yang tinggi sehingga orang awam yang melihat ini mempunyai intepretasinya masing-masing yang membuat kriya menjadi tidak terbatas. Berbicara tentang kriya bukan hanya berbicara tentang materialnya yang khas, namun juga berbicara masalah teknik.

Dalam karya ini juga ingin membahas tentang pertumbuhan dan perkembangan seni rupa khususnya kriya. Seni rupa semakin lama semakin tumbuh. Proses tumbuh yang terjadi seperti halnya pada tumbuhan dipengaruhi oleh sinar matahari yang membantu tumbuhan dalam melakukan fotosintesis. Yang kemudian dianalogikan dalam konteks seni rupa yang berada dalam lingkungan sosial, budaya dan masyarakat tentang akan dibawa kemana, akan tumbuh seperti apa seni rupa sekarang dan masa depan yang semakin tidak tahu arah. Sehingga hal ini menjadi sebuah kritik keberadaan seni rupa khususnya kriya keramik, yang dalam pengertiannya saja sudah semakin meluas, dan seenaknya saja yang akhirnya menjadikan pengertian kriya menjadi tidak terbatas dalam sebuah paradigma sosial. Sehingga dalam hal ini seni rupa dirasa membutuhkan matahari yang dapat membatu dalam menumbuhkan, dan mengarahkan akan dibawa kemana seni rupa sekarang dan masa depan. 


\section{PENUTUP}

Sebuah karya seni dapat terlahir dari ketertarikan, kesukaan, kecintaan akan sesuatu hal, yang sifatnya tidak mutlak, dan setiap orang relatif berbeda-beda. Hal tersebutlah yang terkadang menjadi sebuah kegelisahan yang kemudian menjadi ide atau gagasan untuk melahirkan sebuah karya seni. Meskipun ide dari sesuatu hal yang sama, namun karya yang diciptakan belum tentu sama karena setiap orang juga memiliki imajinasi, pengamatan, dan pola berfikir yang berbeda-beda.

Ide penciptaan tugas akhir "Deformasi Bentuk dan Tekstur Radiolaria dalam Keramik Instalasi" berawal dari sebuah film Life of Pi, sebuah film yang menceritakan tentang seorang pria India yang bernama Pi Patel yang sedang terkatung-katung di atas lautan lepas, hingga pengalamannya melihat laut yang dapat bercahaya. Kemudian di dalam satu bagian film tersebut ketertarikan akan fenomena laut yang dapat bersinar tersebut, hingga menggugah untuk mencari tahu dan menggali informasi tentang kejadian tersebut. Setelah mendapatkan informasi dari internet dan beberapa buku bahwa ternyata yang dapat bersinar di film tersebut adalah Plankton, maka ketertarikan semakin memuncak untuk menelusurinya hingga menemukan kata Radiolaria dan Bioluminesensei. Radiolaria dan Bioluminesensei merupakan sebuah kata asing bagi orang-orang awam. Namun, setelah memahami dan melihat di internet, majalah dan buku tentang Radiolaria, ada kekaguman dan gairah untuk mengubahnya menjadi karya keramik instalasi serta menampilkan peristiwa Bioluminesensi untuk diperkenalkan kepada penikmat seni.

Proses pembuatan karya ini, menggunakan tanah stoneware Sukabumi yang diolah dengan menambahakan waterglass agar tanah cepat kering. Proses pembentukan dilakukan dengan cetak tuang, pinch, dan slab. Sedangkan pendekorasian menggunakan teknik krawang dan teknik coil. Penggunaan teknik hand building merupakan sebuah teknik yang memiliki craftmanship yang tinggi, karena membutuhkan ketelatenan an kesabaran. Namun teknik seperti itulah yang semakin mendekatkan sehingga tercipta keintiman antara perupa dan karya yang dibuat. Setelah proses pembentukan selesai dilakukan tahap pengeringan dengan cara diangin-anginkan. Kemudian bodi yang sudah kering, dibakar biskuit dengan menggunakan tungku gas hingga suhu $800^{\circ} \mathrm{C}$. Setelah itu dilakukan proses pengglasiran dengan teknik semprot, teknik celup dan teknik sabun. Teknik sabun adalah teknik yang memanfaatkan busa sabun yang sudah dicampur dengan pewarna untuk dioleskan pada bodi keramik yang sudah disemprot atau dicelup glasir dasar, lalu dibakar dengan suhu $1180^{\circ} \mathrm{C}$.

Dalam proses pembuatan karya ini ada beberapa kendala dalam pembuatan karya, yaitu bodi keramik yang retak pada saat proses pengeringan yang dikarenakan bahan baku tanah stoneware cair yang digunakan untuk mencetak terlalu banyak pasir. Kendala tersebut menjadi sebuah pembelajaran yang baik untuk dapat berkarya lebih baik lagi di masa yang akan datang.

\section{DAFTAR PUSTAKA}

Astuti, Ambar, (1997), Pengetahuan Keramik, Yogyakarta: Gajah Mada University Press.

Anwar, Anik, (1987), Ringkasan Biology Program $A_{1} \& A_{2}$, Bandung : Ganeca Exact Bandung.

Billington, Dora $M,(1974)$, The Teqnique of Pottery, Rev. ed., London: Bt Basford.

Biological Science Curriculum Study,(1974) Biological Science: An Inquire to Life. Hardcourt, Brace \& World, Inc, Newyork, Chicago, 1963 Limited. 
Dharsono Sony Kartika, Nanang Ganda Pratiwi, (2004) Pengantar Estetika, Bandung: Rekayasa Sains.

Feldman, Edmund Burke, (1967), Art, Image and Idea, New Jersy: Prentic-Hall, Inc Englewood Cliffsd.

Gustami SP, (2004), Proses Penciptaan Seni Kriya, Program Penciptaan Seni Pascasarjana, Institut Seni Indonesia Yogyakarta.

ljong, Frans Grubber, (2015), Mikrobiologi Perikanan \& Kelautan, Jakarta: PT. Rineka Cipta.

Moeliono, Anton M., (1998), Kamus Umum Bahasa Indonesia, Jakarta: Balai Pustaka.

Nontji, Anugrah, (2008), Plankton Laut, Jakarta: LIPI Press.

Ocverik, Otto G, (1994), Art Fundamentals Theory \& Praktis, London: Brown \& Benchmark.

Raharjo, Timbul, (2001), Teko dalam Perspektif Seni Keramik, Yogyakarta: Tonil Press.

Soedarso SP, (2000), Katalogos Pameran Kriya Seni 2000, Galeri Nasional Indonesia Jakarta.

Tim Studio Keramik,(2007), Keramik Buku Teks SMK Petunjuk Praktik Kriya Keramik, Jakarta: Departemen Pendidikan Nasional.

Susanto, Mikke, (2002), Diksi Rupa, Yogyakarta: Kanisius.
www.Radiolaria.org (Akses Tanggal 28 Februari 2106, 20:03 WIB)

www.pinterest.com (Akses Tanggal 8 April 2016 2:08 WIB)

www.morphograpic.com (Akses Tanggal 8 April 2016 2:25 WIB)

www.sciencephoto.com (Akses Tanggal 8 April 2016, 2:29 WIB)

www.myungnaman.co.uk (Akses Tanggal 8 April 2016, 2:31 WIB)

www.geomagz.geologi.esdm.go.id/Radiolariaperunut-batuan-bancuh/

(Akses Tanggal 8 April 2016, 3:00 WIB)

www.becuo.com (Akses Tanggal 5 Mei 2016, 4:00 WIB

\section{WEBTOGRAFI}

